\title{
Hydrothermal Synthesis of Copper Hydroxyphosphate Hierarchical Superstructures and Its Photocatalysis Activity in UV Light
}

\section{Lei Ji}

College of Chemistry and Chemical Engineering, Northeast Petroleum University Provincial Key Laboratory of Oil and Gas Chemical Technology, Daqing, China

1jidqpi@163.com

\author{
Ruimin $\mathrm{Yu}$ \\ College of Chemistry and Chemical Engineering, \\ Northeast Petroleum University Provincial Key \\ Laboratory of Oil and Gas Chemical Technology, \\ Daqing, China \\ ruimin_yu@163.com
}

\begin{abstract}
Copper hydroxyphosphate $\left(\mathrm{Cu}_{2}(\mathrm{OH}) \mathrm{PO}_{4}\right)$ with uniform 3D flower-shaped microsphere hierarchical superstructure was successfully synthesized through a template-free hydrothermal route with ammonia as alkali and complexing agent. This approach provides a facile strategy to synthesize copper hydroxyphosphate crystals with unique morphologies and complex architectures. Several characterization tools including $X$-ray powder diffraction (XRD), UV-Vis diffuse reflectance spectra (UVVis DRS), scanning electron microscope (SEM), and FT-IR were employed to study the phase structures, optical properties, morphologies and characteristic functional groups of the resulting hierarchical superstructures. We further demonstrated the useful photocatalytic activity of $\mathrm{Cu}_{2}(\mathrm{OH}) \mathrm{PO}_{4}$ in the degradation of methylene blue (MB) dye under UV light irradiation. From the analysis of potentials of $\mathrm{Cu}_{2}(\mathrm{OH}) \mathrm{PO}_{4}$, it's theoretically deduced that the photocatalytic degradation of $\mathrm{MB}$ could be attributed to the $\bullet \mathrm{OH}$ and hole rather than $\bullet_{2}{ }^{-}$radicals.
\end{abstract}

Keywords- copper hydroxyphate; hierarchical superstructures; hydrothermal Synthesis; photocatalysi; mechanism s.

\section{INTRODUCTION}

Over the past several years, since the shape and texture of materials have strong effect on their characteristic properties, shape and morphology controlled synthesis has attracted considerable attention ${ }^{\Upsilon 1}$ ${ }^{8]}$. Nanostructured materials with complex architectures may provide higher specific surface areas, which will improve their catalytic properties and selectivity. As an important member of copper phosphate, copper hydroxyphosphate $\left(\mathrm{Cu}_{2}(\mathrm{OH}) \mathrm{PO}_{4}\right)$ is a rare secondary copper mineral that is noted for its deep green color and it has an orthorhombic crystal structure and consists of a $\mathrm{PO}_{4}$ tetrahedron, a $\mathrm{Cu}(1) \mathrm{O}_{6}$ octahedron, a $\mathrm{Cu}(2) \mathrm{O}_{5}$ trigonal bipyramid, and an $\mathrm{OH}$ group between the two $\mathrm{Cu}$ species, in which oxygen atoms are shared with each other.

Copper hydroxyphosphate has been widely investigated due to its novel catalytic effect on oxidation of aromatics by $\mathrm{H}_{2} \mathrm{O}_{2}$, and epoxidation of styrene by $\mathrm{H}_{2} \mathrm{O}_{2}$ or molecular oxygen ${ }^{[9-10]}$. However, until now there were few reports on the fabrication with novel complex architectures and the photocatalysis property of $\mathrm{Cu}_{2}(\mathrm{OH}) \mathrm{PO}_{4}$ under UV light irradiation. Herein, we report a simple hydrothermal route to synthesize copper phosphate complex architectures via a template-free method and investigated its photocatalytic property.

\section{EXPERIMENTAL}

\section{A. Preparation of Catalyst}

All the reagents used in the experiments were analytical grade and used without further purification. Copper hydroxyphosphate crystals was obtained by $\mathrm{Cu}\left(\mathrm{CH}_{3} \mathrm{COO}\right)_{2}$ (hereafter abbreviated as $\left.\left.\mathrm{CuAc}\right)_{2}\right)$ solution and $\left(\mathrm{NH}_{4}\right)_{2} \mathrm{HPO}_{4}$ solution by hydrothermal synthesis method. Synthetic copper hydroxyphosphate crystals were prepared by a mixture of $\mathrm{Cu} / \mathrm{P}$ ratio of $3: 2$ under vigorous stirring at room temperature for $10 \mathrm{~min}$. Prior to the reaction, the $\mathrm{pH}$ of solution mixture was adjusted to different values by $\mathrm{NH}_{4} \mathrm{OH}$ or $\mathrm{CH}_{3} \mathrm{COOH}$ and sonicated in an ultrasonic water bath for $10 \mathrm{~min}$. The bluish slurry mixture was then transferred into a teflonlined stainlesssteel autoclave, which was filled with deionized water up to $80 \%$ of its capacity. The autoclave was heated to various temperatures and maintained at this temperature for 4 hours, and then naturally cooled down to room temperature. The deep green crystals were collected and washed several times with distilled water and absolute ethanol to remove the impurities. The final products were dried at $50{ }^{\circ} \mathrm{C}$ (for more than $5 \mathrm{~h}$ ) for further characterization.

\section{B. Characterization of Catalyst}

The crystal structure of catalyst powder was measured by powder X-ray diffraction (XRD) on a Rigaku D/max IIIB diffract meter with $\mathrm{Cu}-\mathrm{K} \alpha$ radiation at a scanning speed of $5 \% \mathrm{~min}$ ranging from 10 to $70^{\circ}$. The scanning electron microscope (SEM) characterizations were performed on a Zeiss $\Sigma$ IGMA field emission scanning electron microscope. The UV-Vis absorption spectra were measured on TU-1901 UV-Vis spectrophotometer 
(Beijing Purkinje General Instrument Co., Ltd.). UV-Vis diffuse reflectance spectra (DRS) of the samples were also recorded on the above UV-Vis spectrophotometer with an integrating sphere attachment for their reflectance in the range of $200-800 \mathrm{~nm}$, and $\mathrm{BaSO}_{4}$ is the reflectance standard. The FT-IR spectrum of catalyst was recorded on Tensor 27 IR spectrophotometer (Germany Bruker Co., Ltd.).

\section{Evaluation of photocatalytic activity}

The photocatalytic activity of $\mathrm{Cu}_{2}(\mathrm{OH}) \mathrm{PO}_{4}$ was evaluated by degradation of methylene blue (MB) under UV light irradiation in a photoreaction apparatus using a $150 \mathrm{~W} \mathrm{Hg}$ lamp as the light source. An amount of 25.00 $\mathrm{mg}$ of photocatalyst was suspended in a $50 \mathrm{~mL}$ aqueous solution of $1.8 \times 10^{-5} \mathrm{~mol} / \mathrm{L} \mathrm{MB}$. Prior to illumination, the suspension was magnetically stirred in the dark for $30 \mathrm{~min}$ to ensure the establishment of an adsorption-desorption equilibrium between the photocatalyst and MB. During irradiation, $5 \mathrm{~mL}$ of analytical suspension was collected at given time intervals and centrifuged to remove the suspended photocatalyst powders. Then, the UV-Vis adsorption spectrum of the centrifugated solution was recorded using a UV-Vis spectrophotometer. The concentration of $\mathrm{MB}$ was measured at its maximum characteristic absorption at a wavelength of $664 \mathrm{~nm}$ with deionized water as a reference sample. In order to investigate the effects of relevant reactive species, a quantity of different appropriate species quenchers were introduced into the photocatalytic degradation process of $\mathrm{MB}$ in a manner similar to the photodegradation experiment (the light source was a $250 \mathrm{~W} \mathrm{Hg}$ lamp). The dosages of these species quenchers were $0.050 \mathrm{~mol} / \mathrm{L}$, which were enough to investigate the change of photocatalytic degradation rate.

\section{RESULTS AND DISCUSSION}

\section{A. The Influence of Reaction Parameters on The Photocatalysis}

We investigated different reaction parameters including $\mathrm{pH}$ value and reaction temperature. XRD analysis was carried out to investigate the phase structures of the catalysts. Fig. 1 shows the XRD patterns of the asprepared $\mathrm{Cu}_{2}(\mathrm{OH}) \mathrm{PO}_{4}$ at different reaction parameters.
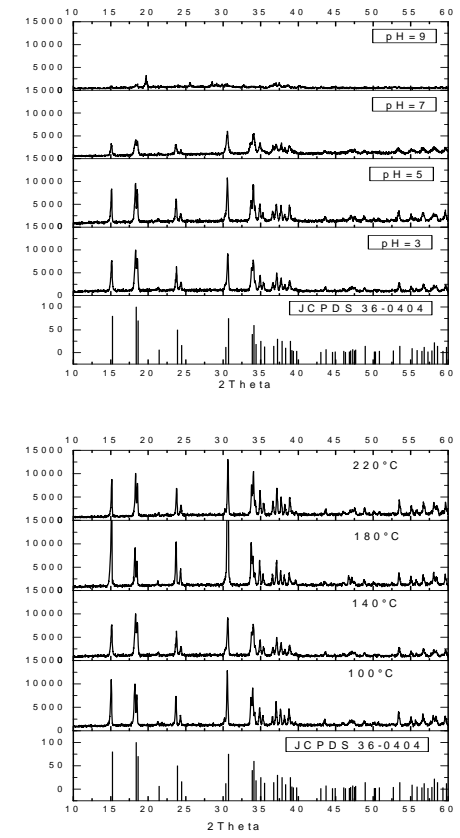

Figure 1. XRD patterns of the as-prepared $\mathrm{Cu}_{2}(\mathrm{OH}) \mathrm{PO}_{4}$ products at (a) different $\mathrm{pH}$ value (reaction temperature were fixed to $\left.140^{\circ} \mathrm{C}\right)$; (b) different reaction temperature $(\mathrm{pH}=3)$. The standard stick pattern for $\mathrm{Cu}_{2}(\mathrm{OH}) \mathrm{PO}_{4}$ (lowest, JCPDS File No. 36-0404).

It shows that $\mathrm{pH}$ value affect the crystalline phases extraordinarily and the as-prepared samples prepared under $\mathrm{pH}=3$ or 5 were well crystallized and all the diffraction peaks can well be indexed to the orthorhombic $\mathrm{Cu}_{2}(\mathrm{OH}) \mathrm{PO}_{4}$ (JCPDS File No. 36-0404). In addition, the diffraction peaks of the samples at different temperature $(\mathrm{pH}=3)$ were sharp and intense, indicating their highly crystalling nature. And no other diffraction peaks of impurity are observed, indicating the phase pure nature of the final product.

\section{B. Photocatalytic properties}

Evaluation of the photocatalytic activies of asprepared samples were carried out via the degradation of MB under UV light irradiation. Fig.2(a,c) show the time profiles of $\mathrm{MB}$ photodegradation as a function of time in the presence of the as-prepared $\mathrm{Cu}_{2}(\mathrm{OH}) \mathrm{PO}_{4}$ under different reaction conditions .

Prior to illumination, an adsorption-desorption equilibrium between the photocatalyst and $\mathrm{MB}$ was established in dark for $30 \mathrm{~min}$. According to the Langmuir-Hinshelwood (L-H) kinetics model, the photocatalytic degradation process of $\mathrm{RhB}$ follows the apparent pseudo-first-order model given by eq. (1).

$$
\ln \frac{C_{0}}{C}=k_{\text {app }} t
$$

Where $C_{0}$ and $C$ are the concentrations of $\mathrm{RhB}$ at initial time and time $t$, respectively, and $k_{\text {app }}$ is the apparent pseudo-first-order rate constant $\left(\mathrm{min}^{-1}\right)$. The $k_{\text {app }}$ values of $\mathrm{Cu}_{2}(\mathrm{OH}) \mathrm{PO}_{4}$ at different reaction parameters were shown in Fig.2(b,d). 

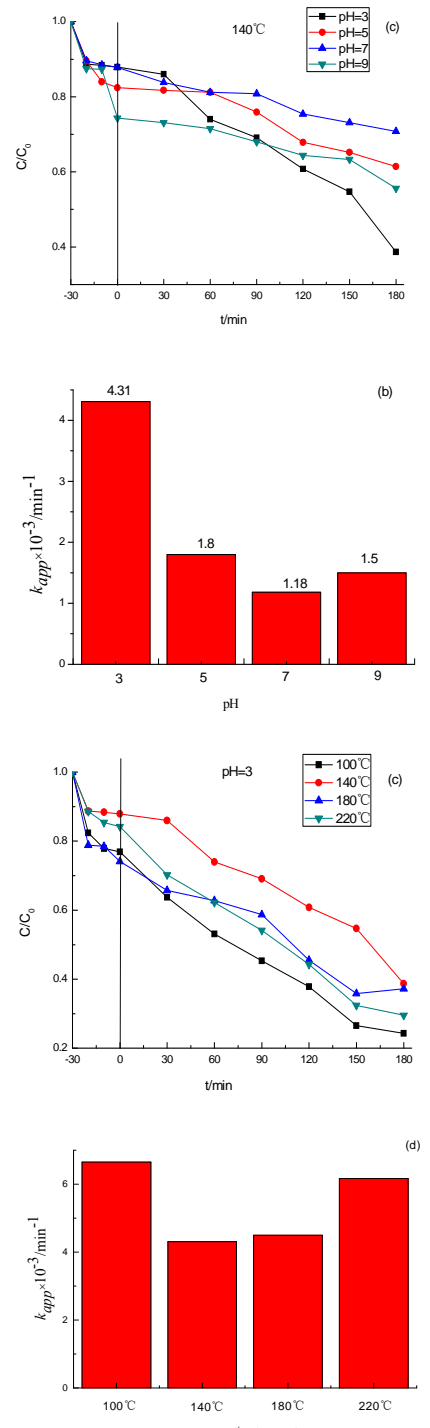

Figure 2. Photocatalytic degradation rate curves (a,c) and $k_{\text {app }}$ values $(\mathrm{b}, \mathrm{d})$ of $\mathrm{Cu}_{2}(\mathrm{OH}) \mathrm{PO}_{4}$ prepared at different $\mathrm{pH}$ value and reaction temperature respectively.

It is observed that with increasing the $\mathrm{pH}$ values, the adsorption ability increase accordingly. But the sample prepared at $\mathrm{pH}=3$ exhibited high photocatalytic activity than the other conditions. Therefore, the adsorption ability is only a factor to accelerate the photocatalysis. Then the $\mathrm{pH}$ was fixed at 3 and the temperature was adjusted from $100^{\circ} \mathrm{C}$ to $220^{\circ} \mathrm{C}$. With increasing temperature, the photocatalytic activity decreased gradually and then enhanced a little at $220^{\circ} \mathrm{C}$. Therefore, the $\mathrm{Cu}_{2}(\mathrm{OH}) \mathrm{PO}_{4}$ synthesis condition was fixed at $\mathrm{pH}=3$ and $100^{\circ} \mathrm{C}$.

\section{SEM Analysis}

The morphology and structure of the as-prepared sample at optimized condition was examined by SEM, as shown in Fig. 3. The image displays that the product was uniform and with diameter of $1-2 \mu \mathrm{m}$ or so. The $\mathrm{Cu}_{2}(\mathrm{OH}) \mathrm{PO}_{4}$ exhibits an hierarchical 3D flower-shaped microsphere superstructure that comprises numerous microplatelets.
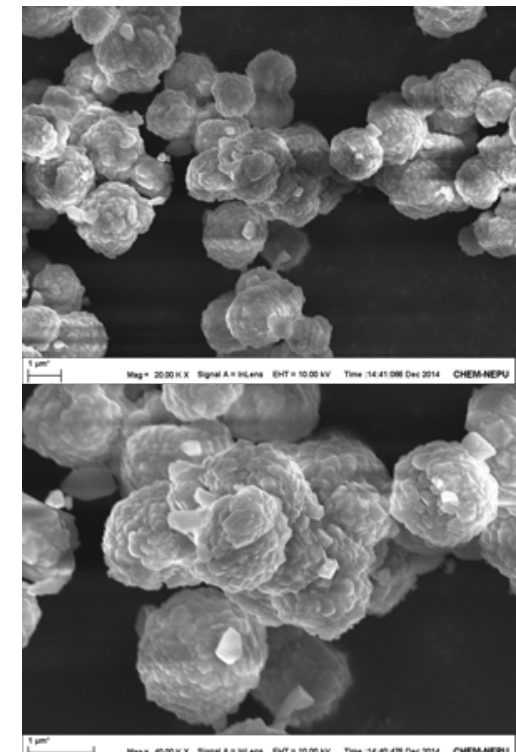

Figure 3. SEM images of $\mathrm{Cu}_{2}(\mathrm{OH}) \mathrm{PO}_{4}$ sample.

\section{FT-IR Analysis}

Fig.4 shows the FT-IR spectrum of the sample prepared at the optimized conditions. The infrared spectrum shows typical adsorption bands at $3454 \mathrm{~cm}^{-1}$, $1630 \mathrm{~cm}^{-1}, 1063 \mathrm{~cm}^{-1}, 947 \mathrm{~cm}^{-1}, 810 \mathrm{~cm}^{-1}, 633 \mathrm{~cm}^{-1}, 603$ $\mathrm{cm}^{-1}, 549 \mathrm{~cm}^{-1}$, and $445 \mathrm{~cm}^{-1}$, respectively ${ }^{[11]}$. The broad bands around $3454 \mathrm{~cm}^{-1}$ and $1630 \mathrm{~cm}^{-1}$ correspond to the stretching and bending modes of the hydroxyls of $\mathrm{Cu}_{2}(\mathrm{OH}) \mathrm{PO}_{4}$ and adsorbed water ${ }^{[12-13]}$. The adsorptions at 1063,947 , and $810 \mathrm{~cm}^{-1}$ can be ascribed to symmetric stretching vibrations of $\mathrm{PO}_{4}{ }^{3-[14-15]}$. The bands at 633,603 and $549 \mathrm{~cm}^{-1}$ are assigned to vibrations of $\mathrm{Cu}-\mathrm{O}$ bond ${ }^{[16]}$. The bands at $445 \mathrm{~cm}^{-1}$ is assigned to symmetric vibrations of $\mathrm{PO}_{4}{ }^{3-[17]}$. The FT-IR result also confirms the formation of pure copper hydroxyphosphate.

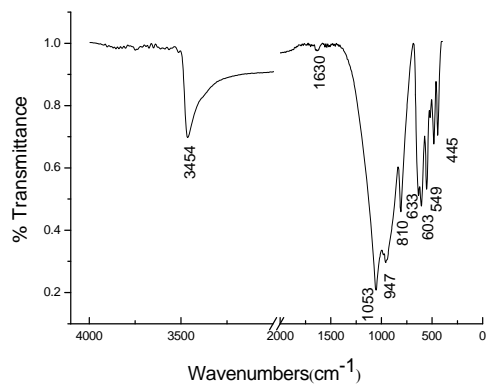

Figure 4. FT-IR spectrum of $\mathrm{Cu}_{2}(\mathrm{OH}) \mathrm{PO}_{4}$ sample.

\section{E. UV-Vis DRS Analysis}

Fig. 5a displays the corresponding UV-Vis diffuse reflectance spectrum (DRS) of the as-prepared product. The product exhibited strong absorption in the UV light region and weak absorption near the Infrared region. The absorption edge of $\mathrm{Cu}_{2}(\mathrm{OH}) \mathrm{PO}_{4}$ was located at about 384 nm. For a crystalline semiconductor, the optical absorption near the band edge follows the formula ${ }^{[18-19]}$ :

$$
a h v=A\left(h v-E_{\mathrm{g}}\right)^{n / 2} \text { (2) }
$$

where $a, v, E_{\mathrm{g}}$ and $A$ are absorption coefficient, light frequency, band gap energy, and a constant, respectively. Among them, $n$ is determined by the type of optical 
transition of a semiconductor ( $n=1$ for direct transition and $n=4$ for indirect transition). Therefore, the $E_{\mathrm{g}}$ of different as-prepared sample can be calculated from a plot of $(a h v)^{1 / 2}$ versus $(h v)$ because the $n$ values of $\mathrm{Cu}_{2}(\mathrm{OH}) \mathrm{PO}_{4}$ is 4 , as shown in Fig.5b. The $E_{\mathrm{g}}$ estimated from the intercept of the tangents to the plots were 3.04 $\mathrm{eV}$ for $\mathrm{Cu}_{2}(\mathrm{OH}) \mathrm{PO}_{4}$.
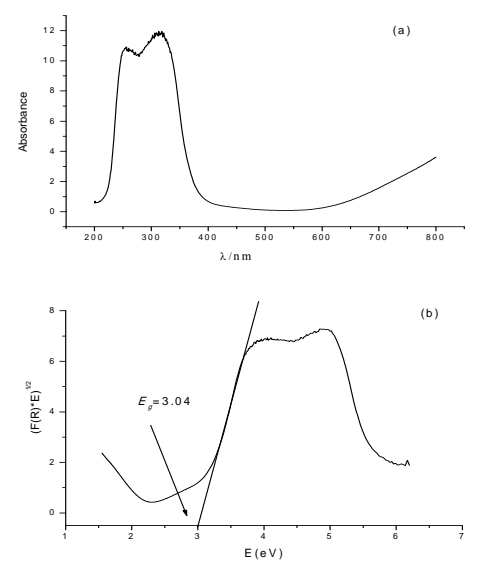

Figure 5. UV-vis diffuse reflectance spectra (a) and the $(\alpha h v)^{1 / 2}$ versus photon energy $(h v)$ curve (b) of the $\mathrm{Cu}_{2}(\mathrm{OH}) \mathrm{PO}_{4}$ respectively.

As well, the valence band (VB) edge position and the conduction band $(\mathrm{CB})$ edge position of $\mathrm{Cu}_{2}(\mathrm{OH}) \mathrm{PO}_{4}$ was also estimated by the following empirical formulas ${ }^{[20]}$ :

$$
\begin{aligned}
& E_{\mathrm{VB}}=X-E^{\mathrm{e}}+0.5 E_{\mathrm{g}} \\
& E_{\mathrm{CB}}=E_{\mathrm{VB}}-E_{\mathrm{g}}
\end{aligned}
$$

where $E_{\mathrm{VB}}$ is the valence band $(\mathrm{VB})$ potential, $E_{\mathrm{CB}}$ is the conduction band (CB) potential, $X$ is the electronegativity of the semiconductor (which is the geometric mean of the electronegativity of the constituent atoms), $E^{\mathrm{e}}$ is the energy of free electrons on the hydrogen scale $(\sim 4.5 \mathrm{eV}), E_{\mathrm{g}}$ is the band gap energy of the semiconductor. Herein, the $E_{\mathrm{VB}}$ and $E_{\mathrm{CB}}$ of $\mathrm{Cu}_{2}(\mathrm{OH}) \mathrm{PO}_{4}$ was calculated to be 3.49 and $0.45 \mathrm{eV}$ respectively.

\section{F. Possible Photocatalytic Mechanism}

In the photocatalytic oxidation process of dye, a series of photo-induced reactive species, including $\mathrm{h}^{+}, \cdot \mathrm{OH}$ or $\cdot \mathrm{O}_{2}{ }^{-}$, will directly take part in this process after the electron-hole pairs are produced by irradiation of photocatalyst ${ }^{[21-22]}$. To evaluate the roles of these reactive species, different scavengers were applied as probes for $\mathrm{MB}$ degradation. In this study, benzoquinone (BQ) ${ }^{[23]}$, isopropyl alcohol (IPA), Methanol $(\mathrm{MeOH})$ and $\mathrm{AgNO}_{3}$ were adopted as the traps for $\cdot \mathrm{O}_{2}^{-}, \cdot \mathrm{OH}, \mathrm{h}^{+}$and $\mathrm{e}^{-}$ respectively. The final concentrations of BQ, IPA, $\mathrm{MeOH}$ and $\mathrm{AgNO}_{3}$ in the reaction system were $0.050 \mathrm{~mol} / \mathrm{L}$. Fig. 6 shows the variation of MB degradation with different quenchers.

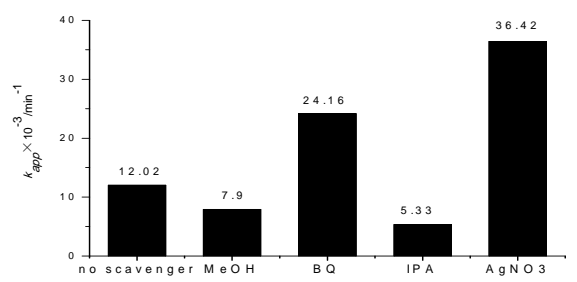

Figure 6. influence of different quenchers to $k_{\text {app }}$ values under UV light irradiation
After addition of IPA, the photodegradation of MB was inhibited significantly, which implies that $\cdot \mathrm{OH}$ radicals played major role in $\mathrm{Cu}_{2}(\mathrm{OH}) \mathrm{PO}_{4}$ system under UV light irradiation. In addition, the $\mathrm{MeOH}$ can inhibited the photodegradation also, which means photogenerated $\mathrm{h}^{+}$played comparatively minor role for $\mathrm{MB}$ degradation. Differently, the addition of $\mathrm{BQ}$ or $\mathrm{AgNO}_{3}$ showed an enhanced effect in the photodegradation of $\mathrm{MB}$. The pathway for the photocatalytic mechanism of $\mathrm{Cu}_{2}(\mathrm{OH}) \mathrm{PO}_{4}$ under UV light irradiation was proposed as shown in Fig. 7.

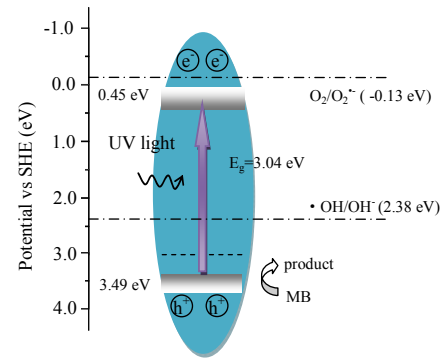

Figure 7. Diagram of the band energy and the photocatalysis mechanism of $\mathrm{Cu}_{2}(\mathrm{OH}) \mathrm{PO}_{4}$.

Under UV light irradiation, the $\mathrm{Cu}_{2}(\mathrm{OH}) \mathrm{PO}_{4}$ can be excited and electron-hole pairs would be generated. According to the band gap structure, the photogenerated electron at the $\mathrm{CB}$ edge potential is more positive than the standard reduction potential of $\mathrm{O}_{2} / \mathrm{O}_{2}{ }^{-}(-0.13 \mathrm{eV})$. As a consequence, the photogenerated electron is not negative enough to reduce $\mathrm{O}_{2}$ to the $\cdot \mathrm{O}_{2}{ }^{-}$radicals. Meanwhile, the photogenerated hole can also immigrate to the $\mathrm{VB}$ of the $\mathrm{Cu}_{2}(\mathrm{OH}) \mathrm{PO}_{4}$. Moreover, the VB potential is more positive than the standard reduction potential of $\mathrm{OH}^{-} / \cdot \mathrm{OH}(2.38$ $\mathrm{eV})$, suggesting that the hole on the surface of $\mathrm{Cu}_{2}(\mathrm{OH}) \mathrm{PO}_{4}$ can oxidize $\mathrm{OH}^{-}$to $\cdot \mathrm{OH}$ and then oxidize the $\mathrm{MB}$ molecular directly. The addition of $\mathrm{AgNO}_{3}$ can quench the photogenerated electron and which can efficiently reduce the recombination of photogenerated electron-hole pairs. Consequently, the amount of $\mathrm{h}^{+}$(or - $\mathrm{OH}$ ) increased and which accounts for the enhancement in photocatalytic activity. BQ as a strong oxidizer can also react with photogenerated electron and then enhance the photocatalytic activity. Form the analysis of potential, it's theoretically reasonable that the photocatalytic degradation of MB could be attributed to the reaction of -OH radical and photogenerated hole.

\section{CONCLUSION}

In summary, the photocatalyst $\mathrm{Cu}_{2}(\mathrm{OH}) \mathrm{PO}_{4}$ with uniform 3D flower-shaped microsphere hierarchical superstructure was successfully synthesized through a template-free hydrothermal method. The optimized synthesis conditions were investigated and which are fixed at $\mathrm{pH}=3$ and reaction temperature is $100^{\circ} \mathrm{C}$. The photocatalytic activity of $\mathrm{Cu}_{2}(\mathrm{OH}) \mathrm{PO}_{4}$ for the degradation of MB at UV light has been observed. On the basis of calculated energy band positions and the effects of scavengers experimental results, the possible mechanism of photocatalytic activities for $\mathrm{Cu}_{2}(\mathrm{OH}) \mathrm{PO}_{4}$ is attributed to the $\bullet \mathrm{OH}$ radical and photogenerated hole. 


\section{REFERENCES}

[1] M. T. Cao, T. F. Liu, S. Gao, G. B. Sun, X. L. Wu, C. W. Hu, Z. L.Wang, , "Single-Crystal Dendritic Micro-Pines of Magnetic a$\mathrm{Fe}_{2} \mathrm{O}_{3}$ : Large-scale Synthesis, Formation Mechanism and Properties," Angewandte Chemie International Edition, vol. 44, 2005, pp. 4197-4210.

[2] A. M. Cao, J. S. Hu, H. P. Liang, L. J. Wan, "Self-Assembled Vanadium Pentoxide $\left(\mathrm{V}_{2} \mathrm{O}_{5}\right)$ Hollow Microspheres from Nanorods and Their Application in Lithium-Ion Batteries," Angewandte Chemie International Edition, vol. 44(28), 2005, pp. 4391-4395.

[3] X. W. Lou, C. M. Li, L. A. Archer, "Designed synthesis of coaxial $\mathrm{SnO}_{2}$ carbon hollow nanospheres for highly reversible lithium storage," Advanced Materials, vol. 21(24), 2009, pp. 2536-2539.

[4] D.Yang, S.Sarina, H. Zhu, H. Liu, Z. Zheng, M. Xie, S. V. Smith, S. Komarneni, "Capturing Radioactive $\mathrm{Cs}^{+}$and $\mathrm{I}^{-}$from Water with TitanateNanofibers and Nanotubes," Angewandte Chemie International Edition, vol.50, 2011, pp. 10594-10598.

[5] Z. Xu, X. Ren, C. T. Sun, X. Zhang, Y. F. Si, C. L. Yan, J. S. Xu, D. F. Xue, "Morphology evolution at nano to micro-scale," Funct. Mater. Lett, vol.1 (3), 2008, pp. 167-172.

[6] S. G. Zhen, C. Di, "Self-Coiling of $\mathrm{Ag}_{2} \mathrm{~V}_{4} \mathrm{O}_{11}$ Nanobelts into Perfect Nanorings and Microloops," Am. Chem. Soc, vol.128(36), 2006, pp. $11762-11763$

[7] A. Mohammadi, J. Badraghi, A. B. Moghaddam, Y. Ganjkhanlou, M.Kazemzad, S. Hosseini, R. Dinarvand, "Synthesis of $\mathrm{Er}_{2} \mathrm{O}_{3}$ Nanoparticles and $\mathrm{Er}_{2} \mathrm{O}_{3}$ Nanoparticle/Polyaniline Deposition on the Surface of Stainless Steel by Potentiostatic Deposition," Chemical Engineering \& Technology, vol. 34(1), 2011, pp. 56-60.

[8] Q. Zhang, W. S. Wang, J. Goebl, Y. D. Yin, "Self-templated synthesis of hollow nanostructures," Nano Today, vol. 4(6), 2009, pp. 494-507.

[9] F. S. Xiao, J. M. Sun, X. Q. Meng, R. B. Yu, H. M. Yuan, J. N. Xu, T. Y. Song, D. Z. Jiang, R. R. Xu, "Synthesis and Structure of Copper Hydroxyphosphate and Its High Catalytic Activity in Hydroxylation of Phenol by $\mathrm{H}_{2} \mathrm{O}_{2}$," Journal of Catalysis, vol. 199(2), 2001, pp. 273-281.

[10] F. S. Xiao, J. M. Sun, X. Q. Meng, R. B. Yu, H. M. Yuan, D. Z. Jiang, S. L. Qiu, R. R. Xu, "A novel catalyst of copper hydroxyphosphate with high activity in wet oxidation of aromatics,"Applied Catalysis A: General, vol. 207(1-2), 1982, pp. 267-271.
[11] Y.Y. Xu, X. L.Jiao, D. R.Chen, "Hydrothermal synthesis and characterization of copper hydroxyphosphate hierarchical superstructures," J.Dispersion Sci. Technol, vol. 32, 2011, pp. 591595.

[12] W. S. Peng, G. K. Liu, "The Charts of the Infrared Spectra of the Minerals, "Beijing: Science Press, 1982.

[13] K. Nakamoto, "Infrared and Raman Spectra of Inorganic and Coordination Compounds," Wiley-Interscience Press, 2008.

[14] M. Klähn, G. Mathias, C. Kötting, M. Nonella, J. Schlitte, K. Gerwert, P. Tavan, "IR Spectra of Phosphate Ions in Aqueous Solution: Predictions of a DFT/MM Approach Compared with Observations," Phys. Chem. A, vol. 108, 2004, pp. 6186-6194.

[15] A.Q. Yuan, S. Liao, Z.F. Tong, J. Wu, Z.Y. Huang, "Synthesis of nanoparticle zinc phosphate dihydrate by solid state reaction at room temperature and its thermochemical study," Materials Letters, vol. 60(17-18), 2006, pp. 2110-2114.

[16] X. L. Jiao, D. R. Chen, W. Q. Pang, Y. Yue, "New route for synthesizing silica-pillared $\gamma$-structure zirconium phosphate," Microporous and Mesoporous Materials, vol. 39(3), 2000, pp. 529535.

[17] I. S. Cho, D.W. Kim, S. Lee, C.H. Kwak, S.T. Bae, J.H. Noh, S.H. Yoon, H.S. Jung, D. W. Kim, K.S. Hong, "Synthesis of $\mathrm{Cu}_{2} \mathrm{PO}_{4} \mathrm{OH}$ Hierarchical Superstructures with Photocatalytic Activity in Visible Light," Adv.Funct. Mater, vol. 18, 2008, pp. 2154-2162.

[18] M. A. Butler, "Photoelectrolysis and physical properties of the semiconducting electrode $\mathrm{WO}_{3}$," Appl. Phys, vol. 48, 1977, pp. 1914-1920.

[19] J. Zeng, H. Wang, Z. Y. Cai, Z. M. Kang, H. Yan, "Hydrothermal synthesis and photocatalytic properties of pyrochlore $\mathrm{La}_{2} \mathrm{Sn}_{2} \mathrm{O}_{7}$ nanocubes, " Phys. Chem. C, vol. 111(32), 2007, pp. 11879-11887.

[20] A. H. Nethercot, Jr., "Prediction of Fermi Energies and Photoelectric Thresholds Based on Electronegativity Concepts,' Phys. Rev. Lett, vol. 33, 1974, pp. 1088-1091.

[21] A.L. Linsebigler, G. Lu, J. T. Yates, "Photocatalysis on $\mathrm{TiO}_{2}$ Surfaces: Principles, Mechanisms, and Selected Results," Chem. Rev, 95, 1995, pp. 735-758.

[22] S. S. Soni, M. J. Henderson, J. F. Bardeau, "Visible-Light Photocatalysis in Titania-Based Mesoporous Thin Films," A. Adv. Mater, vol. 20, 2008, pp. 1493-1498.

[23] M. C. Yin, Z. S. Li, J. H. Kou, Z. G. Zou, "Mechanism investigation of visible light induced degradation in a heterogeneous $\mathrm{TiO}_{2} /$ Eosin Y/Rhodamine B system,” Environ. Sci. Technol, vol. 43, 2009, pp. 8361-8366. 